\title{
Design ANd Optimization OF Production TEChNology OF Thin-WALled VANAdium Parts
}

\author{
Lubos Kroft \& Jindrich Sykora
}
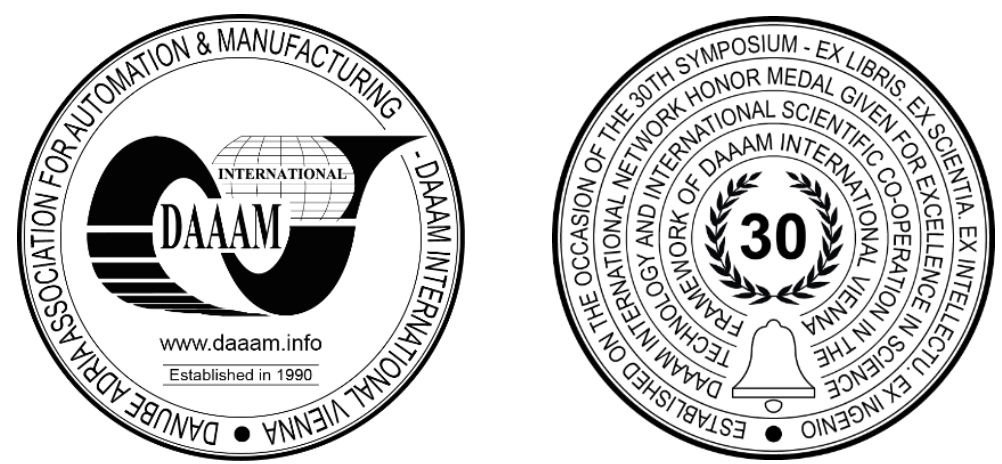

This Publication has to be referred as: Kroft, L[ubos] \& Sykora, J[indrich] (2021). Design and Optimization of Production Technology of Thin-Walled Vanadium Parts, Proceedings of the 32nd DAAAM International Symposium, pp.0209-0214, B. Katalinic (Ed.), Published by DAAAM International, ISBN 978-3-902734-33-4, ISSN 1726-9679, Vienna, Austria

DOI: $10.2507 / 32$ nd.daaam.proceedings.031

\begin{abstract}
This article deals with one of the research directions solved at the Department of Machining Technology of the University of West Bohemia in the field of thin-walled parts machining technology. The main objective of this research was to find suitable conditions for machining parts made of nearly pure vanadium. Materials such as vanadium are used more and more frequently in the industry and their application, for example in medicine, is nowadays much more common. One of the most critical issues in machining vanadium parts is its relatively high toughness combined with low thermal conductivity, which makes its machining characteristics close to materials like titanium. The combination of these material properties together with a thin-walled part and the requirement for very high precision of the product adds up and creates a rather complex problem that needed to be solved so that the whole manufacturing process could be subsequently deployed in a real production environment.
\end{abstract}

Keywords: Machining; vanadium; thin-walled part; manufacturing technology; high precision

\section{Introduction}

The present time brings the use of various non-traditional solutions and their deployment in practice, especially with regard to the continuous development of technology and the desire to achieve higher utility values, reduce economic requirements and also reduce the environmental burden. For this reason, the use of materials with specific mechanical and chemical properties that were previously little used is now quite common. There are many areas dealing with this development, such as the use of hot spraying, superalloys and others. [1] One such material is vanadium. Most people in engineering practice are familiar with vanadium as an alloying element in various alloys. However, its use as a standalone material for the manufacture of machine parts with special properties is still very uncommon today. [5]

The properties of vanadium are very close to those of hard machinable materials [5] In combination with a part with a very thin wall, the whole issue can be considered very complicated. Research on machining vanadium parts has been divided into investigating the properties of vanadium itself and its machining properties. Furthermore, the research focused on machining thin-walled components. Based on this research, an experimental part was carried out where the machining strategy was designed and optimized and the stability of the whole process was tested. 


\section{Properties of vanadium and its machining}

It is a silvery metal that, along with niobium and tantalum, is in the 5th group of metals in the periodic table of elements. Vanadium has a cubic centred crystal lattice. These metals are characterized by their high melting points. Vanadium has come into technical use mainly as an alloying element in the preparation of high-quality steels. In steel, vanadium carbide forms V4C3 and thus increases wear resistance. Other uses are found in titanium and aluminium alloys where it increases the mechanical resistance of the alloys.

The use of vanadium as a main material is even nowadays uncommon, the main disadvantage is, as with almost all pure metals, especially the low hardness. However, thanks to a certain amount of alloying elements it is possible to increase the mechanical properties and the alloy thus achieves particularly high strength, especially at high temperatures, toughness, corrosion resistance and ductility while maintaining a relatively low density. These are properties that make the use of vanadium particularly suitable for certain industries such as the medical, energy or military. The chemical composition and properties of the material used are given in Tables 1 and 2 [1] , [3], [4]

\begin{tabular}{|l|c|c|c|c|c|}
\hline & Oxygen & Nitrogen & Carbon & Hydrogen & Total \\
\hline ppm by weight & 200 & 60 & 50 & 2 & 312 \\
\hline
\end{tabular}

Table 1. Interstitial impurity content of the commercially pure vanadium sample used (ppm by weight) [5]

\begin{tabular}{|l|c|}
\hline \multicolumn{1}{|c|}{ Properties } & Column A \\
\hline Tensile strength & $800 \mathrm{MPa}$ \\
\hline Yield strength & $776 \mathrm{MPa}$ \\
\hline Elastic modulus & $125.5 \mathrm{GPa}$ \\
\hline Poisson's ratio & 0,36 \\
\hline Elongation at break (in $50 \mathrm{~mm})$ & $2 \%$ \\
\hline Hardness, Brinell & 165 \\
\hline Hardness, Rockwell A & 52 \\
\hline Thermal expansion co-efficient $\left(20-100^{\circ} \mathrm{C} / 68-212^{\circ} \mathrm{F}\right)$ & $8.33 \mu \mathrm{m} / \mathrm{m}^{\circ} \mathrm{C}$ \\
\hline Thermal conductivity & $31 \mathrm{~W} / \mathrm{mK}$ \\
\hline
\end{tabular}

Table 2. Mechanical and thermal properties of vanadium [4]

As the main objective of the problem addressed in this research was the machining of this material. Due to its chemical composition and its mechanical and physical properties, it can be expected that during machining the material will stick to the cutting edge and overall machining will be problematic. From a machining point of view, vanadium can be characterised as a material approaching the harder to machine stainless steels of ISO M. In these materials, the high plasticity and toughness of the material results in the formation of a chip which is very difficult to cut. This fact results in complicated setting of cutting conditions with regard to chip leaving the cutting point and also possible damage to the workpiece or tool. [1], [2], [7]

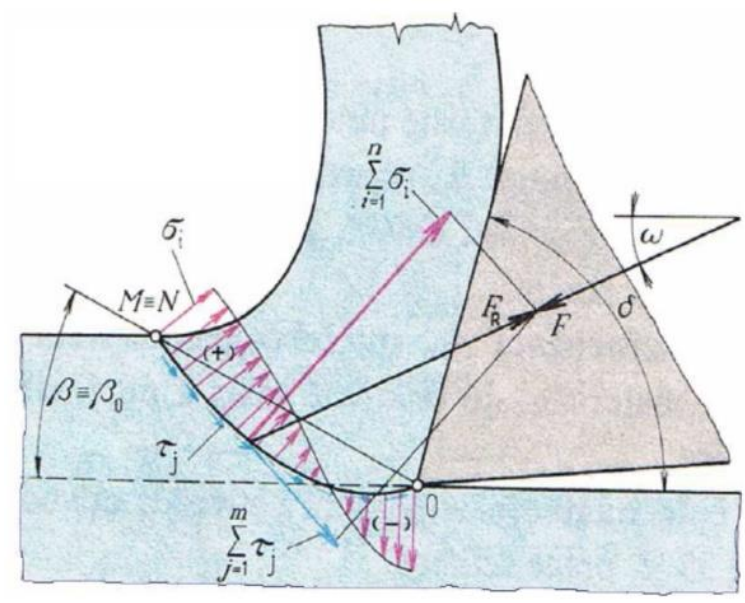

Fig. 1. Stress history in machining of tough materials [2]

Furthermore, the material generates a considerable amount of heat. There are two reasons for the increased amount of heat in these types of material. The main reason is the large amount of heat generated in the area of primary plastic deformation. This heat is generated by the low willingness of the material to separate, i.e. to reach a state of upsetting deformation. This state is due to the high toughness. 
This makes it necessary to supply a much greater amount of energy to separate the individual grains. The formation of deformations in the primary plastic deformation zone is shown in Figure 1. The second factor is the low conductivity of vanadium, where almost all of the heat generated must be absorbed by the workpiece and the tool. This results in significant thermal stress and thus increased tool wear. The difference in heat concentration with respect to thermal conductivity is shown in Figure 2. [3], [8]
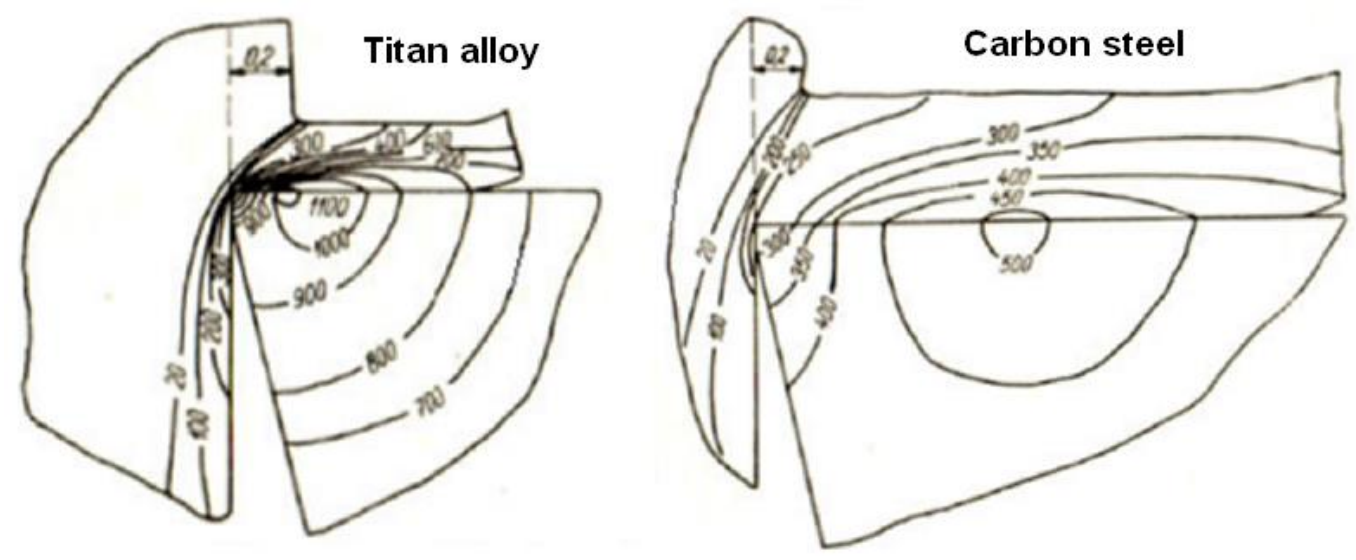

Fig. 2. Schematic representation of turning temperatures in titanium alloy and carbon steel [3]

Compared to stainless steels, however, there is no hardening of the material and the hardness is usually lower. Due to these properties, it is the closest to machining ISO S group materials such as titanium. From all these characteristics it follows that in general vanadium machining as such is possible but has certain specificities that need to be taken into account when designing the technology. [1]

\section{Machining of thin-walled components}

The shape of the part is always crucial when designing a machining strategy. Its geometric dimensions, tolerances and in combination with the material to be machined has a fundamental impact on the design of the machining technology. The desire to reduce the weight of each part as much as possible is logical in terms of saving energy and resources. Most companies today, thanks to advanced modelling algorithms, are trying to optimise the distribution of material on each part to produce parts with very thin walls. While these parts are very suitable from an environmental and economic point of view, they are not so suitable from a machining point of view. The machining of thin-walled parts involves a number of major complications and if the part is made of, for example, stainless steel or one of the ISO S materials such as titanium or Inconel it is often a very complex issue.

Machining thin-walled components involves a number of problematic factors that must be taken into account when designing the technology. One of the fundamental problems arising on very thin wall parts is vibration. The generation of vibration is fundamentally linked to the machining process itself and cannot be avoided to some extent, but it can be minimised. However, if the vibration exceeds a certain value, it is a spontaneous vibration of the whole assembly, and this is a phenomenon in machining in a second of cases caused by the instability of the process and is sought to be avoided. If vibrations occur, it is necessary to adjust the cutting conditions, the machining strategy, change the cutting tool or intervene in other ways. In most cases, vibration has very negative consequences such as damage to the part, the tool or the machine. In the case of thin-walled parts, the occurrence of vibration is probably the most common problem associated with their machining and therefore considerable attention must be paid to the setup of the entire process.
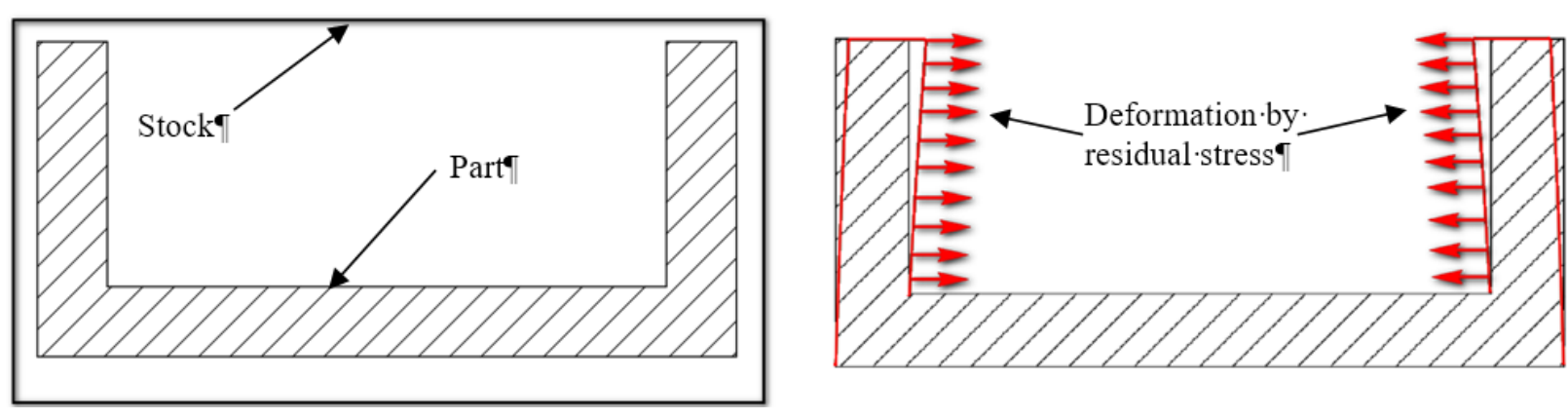

Fig. 3. Possible deformation of the part at the base of uneven material removal 
Another very common phenomenon occurring when machining thin-walled parts is shape deformation or dimensional instability. This is due in most cases to internal stresses in the part which are caused by the removal of the blank material. The removal of large amounts of material results in an uneven distribution of stresses and these forces can then deform the part. There are a number of methods to try to avoid this problem. One of these is the appropriate choice of machining strategy, not only with regard to manufacturability itself, but specifically to internal stresses. Thus, it is common for thinwalled parts to be machined in multiple clamping operations precisely to compensate for the stresses induced by material removal. Another option is to include suitable heat treatment to reduce the internal stress, obviously taking into account whether the rest of the part allows it. One final option, used for example in high-volume production, is to adapt the machined shape to the previously calculated deformations. Here, it is possible to design a modification of the shape of the machined part so that, after accounting for the deformations, the workpiece will conform to the desired shape. This method is very efficient, but requires very precise calculations and also a considerable amount of experience to find a suitable procedure for the whole process. In spite of the methods mentioned, the production of a thin-walled ring in which $95 \%$ of the material inside and only $5 \%$ outside has to be removed will always be very complicated, despite the fact that circular profiles have the most suitable shape with regard to deformation.

There are a number of problems in machining thin-walled parts, but the last one, which is also connected with parts made of materials that generate a lot of heat during machining, is the removal and possible consequences of excessive heat accumulation in the workpiece. When machining materials with low thermal conductivity, it is necessary to take into account that the heat generated during machining is not dissipated as it is for example in carbon steels, but the distribution of heat dissipation is completely different. By default, the greatest amount of heat is dissipated through the chip where a significant amount of heat is also generated. The problem of low conductivity is that the workpiece material does not absorb as much heat as would be required and the heat accumulates in the area of primary plastic deformation. Here it is then distributed to other parts that are in direct contact with the region of origin. Thus, apart from the tool and the environment, much more heat is concentrated in the workpiece. Due to the low conductivity, the heat is absorbed slowly, but due to the low wall thickness, there is much less heat to induce thermal deformation. This fact then manifests itself again in shape deformation or dimensional instability. [6]

In engineering practice, all of the above factors usually occur to some extent simultaneously and it is therefore always necessary to find the appropriate combination of cutting conditions, machining strategy, cutting tool and a range of other parameters to achieve the required quality and dimensional accuracy of the part. In addition to those mentioned above, a number of factors such as tool wear, cutting forces, clamping method and many others intervene in the process. However, these are not the dominant effect of machining thin-walled parts or parts made of difficult to machine materials and their analysis will therefore not be dealt with further in this article.

\section{Test subject and experimental methods}

A part for medical development was selected as the test sample. It is a special capsule designed for further experiments. Unfortunately, further details cannot be disclosed due to cooperation with the test sponsor. The tested samples are shown in Figure 4. The larger part is called the capsule and the smaller cap. These are two parts that are supposed to fit together. After inserting the experimental sample into the capsule, the capsule is closed with the cap and then the two parts are welded together using an electron beam.
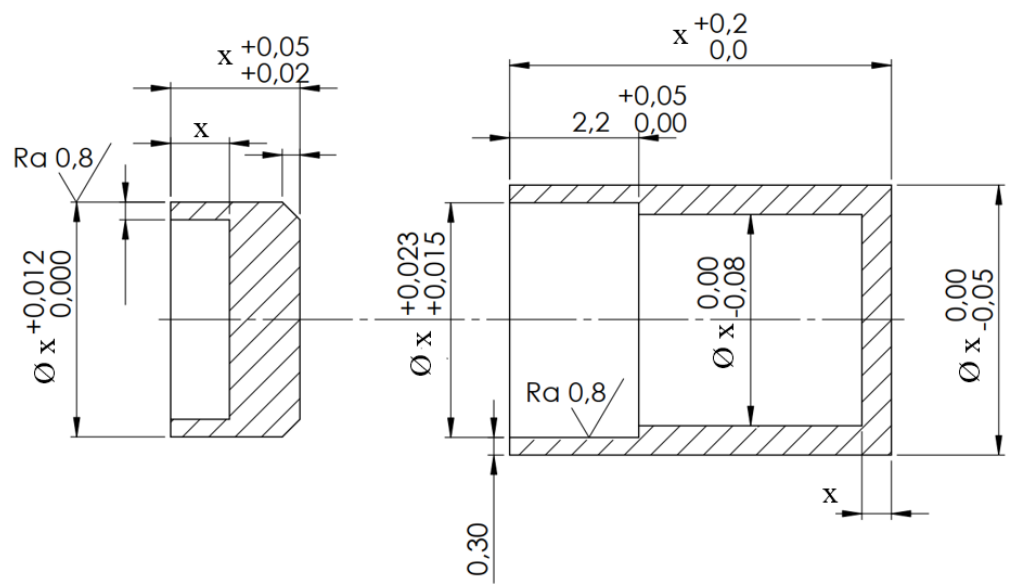

Fig. 4. Tested part, with respect to secret data, is a drawing without basic dimensions only with tolerances

From a machining perspective, these are very precise parts, and in particular the two diameters that fit together have very close tolerances, down to $0.008 \mathrm{~mm}$. This tolerance is very thin with a wall length of $2.2 \mathrm{~mm}$ and a wall thickness of $0.3 \mathrm{~mm}$ and problems were expected. Such tight tolerances are there with respect to electron beam welding so that the least possible layer is affected. Other problem areas can be found in the corners where there was a requirement for minimum corner radii. 
All these constraints had to be taken into account when designing the machining strategy. The experiments were conducted in two phases. In the first phase, the appropriate tools and their sequence were sought with respect to the deformation of the part and the achievement of geometric dimensions. In the second phase, the production of the part was carried out with respect to the compliance with the overall tolerances and to establish the stability of the process. After each of the tests, the experimental sample was taken to the metrology laboratory and all the necessary dimensions were measured. Based on these results, the whole process was then optimised and further testing was carried out.

\section{Experiments and their evaluation}

With regard to the shape of the part, turning was chosen as the initial machining. The part was manufactured from a solid round bar with a diameter of $6 \mathrm{~mm}$. As mentioned above the first exception was the choice of tooling. The tooling assembly was chosen mainly to achieve the required dimensions and tolerances, but also according to the tooling of the machine used. The machine used was an EMCO MAXXTURN 25 turning centre.

The first operation was the alignment of the face. Here, a standard corner turning tool with a replaceable insert was used. The same tool was then used for the longitudinal external turning. Given the size of the parts and the requirement for minimum radius dimensions at the corner, a monolithic carbide tool with a tip radius of $\mathrm{r}=0.1 \mathrm{~mm}$ was chosen for the internal turning. Before finishing, the hole was drilled with a monolithic drill bit. Allowances for all finishing operations ranged from $0.08 \mathrm{~mm}$ to $0.15 \mathrm{~mm}$ depending on the tool radius used.

Despite considerable efforts to find suitable cutting conditions for the above strategy, it had to be stated that it was not possible to achieve the required dimensions in a repeated production of only a few pieces. The main problematic element would be the dimension with a tolerance of $0.008 \mathrm{~mm}$, where the turning tool showed considerable instability with regard to uneven chip formation and chip evacuation. Therefore, based on experience, finishing was carried out using a milling operation. This was a three-axis spiral milling of a circular pocket. A monolithic milling cutter with a very small corner radius and also a very small edge rounding was used as a tool, thus ensuring that tool deburring did not occur. The milling strategy also greatly improved chip evacuation by forming an articulated chip that was much easier to remove from the cut point.

Unfortunately, even after this improvement, the result was not satisfactory. The required surface roughness of the inner diameter was problematic. After several test passes it was found that vibration was occurring. This vibration was caused by the surface waviness after the drilling operation. The final optimization step was therefore to include a milling operation before the finishing operation. Also, the size of the drill bit was reduced so that there was sufficient allowance and the surface waviness could be safely removed. This optimised strategy already met the requirements, both for accuracy and surface quality. The whole course of optimization of the machining strategy is shown in Table 3 . Table 4 shows the cutting conditions for each tool used.

\begin{tabular}{|c|c|c|c|c|c|}
\hline Strategy I & Tools used & Strategy II & Tools used & Strategy III & Tools used \\
\hline Face turning & $\begin{array}{c}\text { CCMT 09T308 } \\
\text { FM }\end{array}$ & Face turning & $\begin{array}{c}\text { CCMT 09T308 } \\
\text { FM }\end{array}$ & Face turning & $\begin{array}{c}\text { CCMT 09T308 } \\
\text { FM }\end{array}$ \\
\hline External turning & $\begin{array}{c}\text { DCGT 11T304 } \\
\text { SF3 }\end{array}$ & External turning & $\begin{array}{c}\text { DCGT 11T304 } \\
\text { SF3 }\end{array}$ & External turning & $\begin{array}{c}\text { DCGT 11T304 } \\
\text { SF3 }\end{array}$ \\
\hline Drilling & Drill - 3xD -IK & Drilling & Drill - 3xD -IK & Drilling & Drill - 3xD -IK \\
\hline Internal turning & $\begin{array}{c}\text { PICCO L 050.3- } \\
10\end{array}$ & $\begin{array}{c}\text { Finishing } \\
\text { milling }\end{array}$ & $\begin{array}{c}\text { Helix solid } \\
\text { carbide endmills }\end{array}$ & $\begin{array}{c}\text { Semi-finishing } \\
\text { milling }\end{array}$ & $\begin{array}{c}\text { Helix solid } \\
\text { carbide endmills }\end{array}$ \\
\hline & & & $\begin{array}{c}\text { Finishing } \\
\text { milling }\end{array}$ & $\begin{array}{c}\text { Helix solid } \\
\text { carbide endmills }\end{array}$ \\
\hline
\end{tabular}

Table 3. Development of a machining strategy for the test piece

\begin{tabular}{|c|c|c|c|}
\hline Tools used & $\begin{array}{c}\text { Cutting speed } \\
\mathbf{v}_{\mathbf{c}}[\mathbf{m} / \mathbf{m i n}]\end{array}$ & $\begin{array}{c}\text { Feed rate } \\
\mathbf{f}_{\mathbf{n}}[\mathbf{m m} / \mathbf{o t}]\end{array}$ & $\begin{array}{c}\text { Deep of cut } \\
\mathbf{a}_{\mathbf{p}}[\mathbf{m m}]\end{array}$ \\
\hline CCMT 09T308 FM & 100 & 0,1 & 0,1 \\
\hline DCGT 11T304 SF3 & 100 & 0,15 & 0,5 \\
\hline Drill - 3xD -IK & 60 & 0,06 & - \\
\hline PICCO L 050.3-10 & 35 & 0,08 & 0,15 \\
\hline $\begin{array}{c}\text { Helix solid carbide } \\
\text { endmills }\end{array}$ & 80 & 0,12 & 0,25 \\
\hline
\end{tabular}

Table 4. Cutting conditions for individual tools 
The last point of the optimization was the verification of the chosen strategy during the production of the test batch. It consisted of 8 pieces of the whole chapel assembly, i.e. the cap and the capsule body. This series was used to test both the tool life and the reliability of the process. The lifetime results were satisfactory. The tools selected after the test series showed only minimal wear and no significant change of operation was required. The only minor problem was the chip material sticking to the cutting edges of the cutter used. This problem was eliminated by using a tool with a different type of coating. In terms of process reliability, $100 \%$ reliability was achieved after the inclusion of the pre-finishing operation. After production debugging, all tolerances on all parts were in the middle of the tolerance range. Based on these results, it was possible to conclude that the desired goal was achieved. The entire machining strategy will then be deployed at the customer's site and only after testing it will it be decided whether it is necessary to proceed with further investigation.

\section{Conclusion}

The whole problematic dealt with in this article was related to the machining of very thin parts made of difficult to machine materials. In the course of the investigation of the whole problem, the material to be machined was described, which was almost pure vanadium. This material is not a very common material and so it was necessary to describe the expected behaviour of the material before the actual tests could begin. It was then necessary to focus on the main problematic features of the part. This was the very weak walls and also the very tight tolerances of some dimensions. The machining strategy used was also chosen with this in mind.

In the course of the experiments it was found that for a given combination of the material to be machined and the shape and tolerances of the part, milling is a preferable strategy to turning despite the rotational shape of the part. After analysis of the results obtained, this was attributed to poor chip evacuation caused by heat build-up and increased plasticity of the material. After using the milling strategy and with the inclusion of a pre-finishing operation, the desired results were achieved. The overall stability of the process was verified by producing a test batch.

The results presented within this research serve both for finding a suitable technology for the production of the given component, but also as a basis for further research in the field of machining of thin-walled parts made of difficult to machine materials, which are currently given considerable attention.

\section{Acknowledgments}

This article was created under the project SGS-2019-008: Research and Development for Innovation in the Field of Manufacturing Technology - Machining Technology III.

\section{References}

[1] Zatloukal, T., Rehor, J., Fulemova, J. \& Povolny, M. (2020). Optimization of the Machining Process of NiCrBSi Thermal Spraying. Proceedings of the 31st International DAAAM Symposium 2020. DAAAM International Vienna, 2020, 0632-0637. DAAAM Proceedings. ISBN 9783902734297. Available from: doi:10.2507/31st.daaam.proceedings.087

[2] Strnad, T. (2011). Machinability of Austenitic Steel. Pilsen, Internal documents -DMT - UWB. University of West Bohemia.

[3] Mikovec, M. \& collective. (1963). Machining of Difficult to Machine Materials; Praha: State Publishing House of Technical Literature. SNTL, 1963, 316 s. ISBN: 04-220-63.

[4] Vanadium - Mechanical Properties and Material Applications [online]. 2012 [cit. 2021-10-18]. Available from: https://www.azom.com/article.aspx?ArticleID=7643

[5] Henshall, G. A. a S. G. (1993). Torres. Tensile Properties of Commercially Pure Vanadium from Room Temperature to $1200^{\circ} \mathrm{C}$. USA: Livermore National Laboratory, , 38.

[6] Masoudi, S., Amini, S., Saeidi, E. \& Eslami-Chalander, H. (2015). Effect of Machining-Induced Residual Stress on the Distortion of Thin-Walled Parts. The International Journal of Advanced Manufacturing Technology. 2015, 76(14), 597-608. ISSN 0268-3768. Available from: doi:10.1007/s00170-014-6281-X

[7] Baksa, T., Schornik, T., Adamek, P. \& Miroslav Zetek. (2016). Machining of Inconel 718 Using Uncoated Cutting Tools with Different Cutting Edge Quality. Proceedings of the 27th International DAAAM Symposium 2016. DAAAM International Vienna, 2016, 0441-0446. DAAAM Proceedings. ISBN 9783902734082. Available from: doi: $10.2507 / 27$ th.daaam.proceedings.065

[8] https://www.sandvik.coromant.com/cs-cz/knowledge/materials/pages/workpiece-materials.aspx, (2018). Machined Materials, Accessed: 2021-10-10 